\title{
Research on Current Situation of Medical Students' Ethics and Teaching Strategies of Medical Ethics
}

\author{
Guohong Wang, Kena Wang* \\ Qiqihar Medical University, Academy of Marxism, Qiqihar City, Heilongjiang Province, 161006
}

Keywords: medical students; current status of medical ethics; medical ethics; teaching strategies

\begin{abstract}
Implementing ideological and political education for medical students in medical colleges and universities and implementing medical ethics education is a crucial aspect. It can not only actively cultivate the higher ideological and moral qualities of medical students, but also can promote the medical students' cognitive level of medical ethics. However, there are still many problems in the work of medical ethics education that need to be improved. It has become a common consensus to strengthen and improve the teaching quality of medical ethics. The paper analyzes the status quo of medical students' medical ethics, and at the same time proposes scientific and effective strategies and methods for enhancing and improving the teaching level of medical ethics.
\end{abstract}

\section{Introduction}

Medical ethics is medical ethics. It covers the professional ethics of doctors and the quality qualities that they need to possess. It also involves medical ethics norms that doctors need to recognize. During the development of the medical and health industry, medical ethics is a key component, and medical ethics education is already an important channel for higher medical schools to cultivate moral quality and medical ethics. In addition, medical ethics belongs to the core curriculum of medical humanities education. The quality of its teaching quality can have a serious impact on the effectiveness of humanistic education. Therefore, adopting a scientific teaching model is particularly critical and has great practical significance.

\section{Analysis of Medical Students' Medical Ethics}

At present, medical ethics education courses offered by most medical colleges and universities are not sufficient, and they are usually taught to lower-level medical students. Because some theoretical knowledge does not have a close connection with real life, it is not easy for medical students to digest, absorb and master knowledge well. This situation will make the teaching work an empty slogan. There is no practical significance. Students cannot establish a higher belief in medical ethics. Moreover, in the actual practice period, medical ethics education theory cannot be applied in medical health practice. In addition, some colleges and universities did not fully contact medical ethics and behavior norms, performance indicators, which makes a serious lack of systematic training programs for medical ethics, leading to medical ethics education work does not have a good orientation and leadership.

During the basic knowledge study in medical colleges, students do not come into contact with real patients and have little clinical practice experience. Therefore, after the clinical practice is implemented, when students are exposed to various difficult problems, the medical students will often Frustrated and overwhelmed. At the same time, during practical courses and internships implemented in some medical colleges, they focus only on the content of students' professional practice, and pay attention to the medical technology level of students. Excessive emphasis must be observed on the rules and regulations and disciplines of all hospitals. And neglect to cultivate its higher medical ethics. Therefore, the students did not have a good degree of medical ethics. During the exchanges with patients, various problems often occurred, which made the contradictions between doctors and patients prominent. For example, without a high degree of service awareness, 
the patient is usually not proactively communicating with the patient, not paying attention to the patient's actual needs and answers to doubts, lack of empathy and empathy, which will make the patient lack trust and the sense of security leads to various dissatisfactions among the patients; weak language communication skills, improper use of words and words, lack of attention to the feelings of the patients, and improper handling of the problems; some medical students cannot handle their emotions well and face patients. It is often impatient and aversive.

At present, many medical staff in hospitals do not have a good medical ethics and morality. The belief in medical ethics is weak or absent. It only pays attention to the pursuit of material interests, and it has the unpleasantness of seeing a doctor and the lack of standard fees. For example, some doctors are innocent or not, open the most expensive drugs, and increase the economic burden on patients; some doctors and their colleagues do not work well together, have a phenomenon of interest disputes; do not pay attention to new knowledge and new technologies The study and application of the game are inconceivable in the case of incurable diseases. Therefore, under such unhealthy circumstances, medical students are often vulnerable to bad habits, resulting in failure to properly perform the effects of medical ethics education, resulting in poor morality of medical ethics, and continuing to deepen conflicts between doctors and patients.

\section{The Current Implementation of Medical Ethics}

A phenomenon that is currently prevalent in medical schools in our country is "reinforcing medical ethics." Some schools believe that medical ethics is an optional course and will not have a major impact on the future development of medicine. Even some schools set it up as elective courses, and greatly reduced the number of hours. In terms of teaching, high-quality specialized teachers are not selected for teaching and teachers of other disciplines are randomly assigned to teach. As a result, medical ethics has developed in a marginalized environment. The knowledge system of medical ethics is tedious and abundant, and it must rely on enough hours and detailed explanations before it can achieve its content. However, the actual survey results show that few colleges and universities can set a sufficient amount of school hours (60 hours as the standard), most of them are about 30 hours, and even less is only 8 hours. Compared to developed countries such as the United States and Japan, and 150 hours of class time for similar courses, China is far from meeting the required standards. Due to lack of class hours, the construction of courses that hinder medical ethics has restricted the medical students' comprehensive and in-depth study of medical ethics.

A typical feature of medical ethics is its practicality, so its theory can be closely linked with reality. However, due to the influence of various factors, such as teaching materials and inadequate practical conditions, the actual teaching content of medical ethics is relatively insignificant. It is only a superficial approach. Mainly studying is the principle of socialist medical ethics in China, related medical ethics and standards, and some of the so-called medical frontier issues (brain death, euthanasia, etc.). It does not deeply investigate the medical ethics of medical practitioners in various medical practices, so there is a general phenomenon, which makes the "fall" between teaching and the actual situation very significant, resulting in reducing the quality and role of education and teaching. In addition, the reality exists in many bad performances of medical ethics in society, which also leads to traditional medical ethics teaching is not easy to justify, reduce student's enthusiasm for learning, but also often produces rebellious psychology.

The choice of teaching mode can often profoundly influence and change the final effect of teaching, and is an important guarantee for effectively improving teaching quality, and it has a multiplier effect. However, looking at the current situation of medical ethics in our country, most of them tend to adopt relatively lagged traditional teaching methods. Even if teachers adopt new methods to impart knowledge, they are often in superficial form and fail to fully display their substantive effect. In the past, teaching only emphasized the examination of students' achievements. Students would appear to cope with the examination as a learning goal. There was no real interest in learning. Usually, as long as they mastered the examination content and knowledge, good results would be achieved. 
Medical ethics belongs to an interdisciplinary field. Teachers who teach this course must have high professional qualities, medical skills, and ethical multidisciplinary abilities. However, the actual teaching situation is that many teachers cannot meet the above criteria, and there is no good teaching background for the composite subject. For example, some teachers belong to the background of humanities and social sciences such as philosophy, and have no medical knowledge reserves; some teachers, although they graduate from medical majors, do not have knowledge of ethical knowledge. Therefore, the actual teaching state is that the background of humanities and social sciences teachers will pay attention to the teaching of ethical and humanistic knowledge, seldom relates to medical content, and the phenomenon of disjointedness; medical graduate teachers, too much attention to medical knowledge content, It is out of touch with the humanistic connotation. Therefore, a serious lack of high-quality compound teacher talent limits the development of medical ethics.

\section{The Effective Way to Improve the Teaching Quality of Medical Ethics}

Medical colleges and universities should use their rich teaching resources to systematically train teachers who are only liberal arts backgrounds, master the actual scenes of future medical students' work, and improve the noble medical ethics that medical personnel must possess. For teachers who only have a medical background, the training of human knowledge can be explained through the methods of their own institution, humanities and social science teachers or external teachers. In addition, medical colleges and universities should actively employ high-quality compound teachers and provide good treatment. From the perspective of long-term development, it is necessary to enhance the cultivation of high-end talents in medical ethics, and actively encourage medical schools to establish the master's degree and doctoral points, and the first-level disciplines and second-level disciplines are set to ethics and medical ethics respectively. At the same time, he was awarded a master's degree in philosophy and doctoral degree, and introduced graduates into medical ethics teaching and research teams in medical colleges.

Medical ethics not only has a strong ideological and political education function, but also plays a major role in medical literacy education. Literature and medical ethics are both important components of medicine and doctor literacy. During the implementation of medical ethics teaching, students should be able to master the medical ethical knowledge that they may come into contact with in their future work, and define theoretical requirements. Under the premise of knowledge learning, they should build a good ethical ability to analyze the actual medical problems. Medical ethics is a part of medical basic courses. The discipline orientation and goals of medical ethics make it necessary for teachers to strictly integrate ethical knowledge with medical knowledge during instruction, and the direction of insisting teaching is knowledge learning. Emotional cultivation and ability training are highly unified and coordinated development. Ultimately, medical students have a good knowledge accumulation, establish a higher concept of humanistic medicine and professional quality, and have the ability to analyze and solve problems on their own.

The medical ethics knowledge system is relatively rich. According to the current implementation of the medical ethics textbook preparation method, the content can be divided into two major modules, namely the medical ethics theory and the medical ethics theory. Among them, the content involved in the general commentary is the outline of medical ethics, the theoretical formation and theoretical basis of medical ethics, the development of medical ethics, and the system of medical ethics. It focuses on cultivating students' ethical concepts and knowledge. The other part of the dissertation mainly deals with ethics of medical relations, management ethics of medical and health services, and ethics of clinical diagnosis and treatment. It is necessary to give full consideration to the specific state of each professional, carry out professional research, highlight key contents, and Medical students analyze the ability to solve problem-solving and promotion. At the same time, during the formulation of the teaching plan, we should follow the actual needs of each professional to carry out targeted selection.

The principles for selecting teaching methods include teaching methods and teaching indefinite methods, which can be specifically related to lecture method, discussion method, situational 
simulation method, case analysis method, intuitive demonstration method, etc., to effectively increase the attractiveness of teaching and enhance teaching. For example, the intuitive demonstration method can use multimedia technology make full use of good pictures, video and other means, intuitive display to students, for their senses to perform good stimulation. Using this method, it can be applied to the clinical diagnosis and treatment ethics lectures, broadcast video footage of medical accidents, and coordinate the relevant medical ethics standards to help students understand the significance of the implementation of the standard operating procedures in the clinical diagnosis and treatment process, enhance the sense of responsibility; During the simulation method, a similar situation was set up for the students to teach the same content, the students were divided into role-playing, and the questions were elaborated on their respective positions. Specifically, it can be used in the teaching of medical interpersonal ethics and so on, allowing students to act as doctors, nurses, patients, family members, etc., and set up specific tasks to complete. After that, each person will discuss and implement the entire process. Distill the relevant knowledge to achieve sublimation of what you have learned.

\section{Conclusion}

Medical ethics belongs to the core curriculum of medical humanities education. Its teaching quality and effect can have a significant impact on medical students' medical ethics and humanistic education. Based on the current medical ethics of medical students, it is necessary to actively improve the existing phenomena, explore effective medical ethics education methods, strengthen the importance of medical ethics awareness, and constantly innovate teaching models and methods to make it truly To contribute to the cultivation of medical students with outstanding medical ethics, to play its important practical significance.

\section{Acknowledgements}

Fund Project: Chinese Medical Association's Topic "Study on Humanistic Quality Education Model Based on Professional Spirit in Applied Medical Colleges" (Project No. 2016B-RW036, Person in Charge: Cui Guangcheng) "Issue and Politics Teaching TCM Student Humanities Quality Education Evaluation Methodology Research and Practice

\section{References}

[1] Huang Danhua. Current status of medical ethics in medical students and teaching strategies of medical ethics [J]. Chinese Medical Ethics, 2011(03):295-297.

[2] Luo Yizhen, Lin Zhenhua, Yu Lina, Lian Xingji, Liang Yi, Li Liping. Subjective evaluation of effectiveness of "service-learning" model of medical ethics in school and graduate medical students [J]. Chinese Medical Ethics, 2014(04): 500-502.

[3] Wang Quanhai, Li Huaibin. On the integration of medical ethics education in basic medical morphology experiment teaching [J]. Chinese Medical Ethics, 2016(02): 348-350.

[4]Wen Min. Exploration of the path of integration of socialist core values into the medical ethics of medical students [J]. China's Out-of-school Education, 2016(27):89+91.

[5] ZHAI Rui. Investigation on the current status of medical ethics in medical students and suggestions for the cultivation of medical ethics [J]. Journal of Mudanjiang Medical College, 2015(02): 129-131.

[6] Fu Yang, Yin Mei. The importance of the communication courses for doctors and patients in clinical specialties in medical colleges and universities [J]. Chinese Medical Ethics, 2015(03): 436-438.

[7] Lin Yuan. The current situation of medical students' medical ethics and educational countermeasures in the new situation [J]. Chinese Health Industry, 2017(32): 192-193.

[8]Guo Yaheng, Qu Dongxu. Current status and educational countermeasures of medical ethics among medical students in Henan province [J].Hygiene Vocational Education, 2018(02):152-153. 